\title{
CONTRADICTORY REASONING CONNECTING WITH THE PROBLEMS OF INTELLIGENT ROBOTRONICS
}

\author{
Roman Khelemendik \& Valentin Pryanichnikov
}
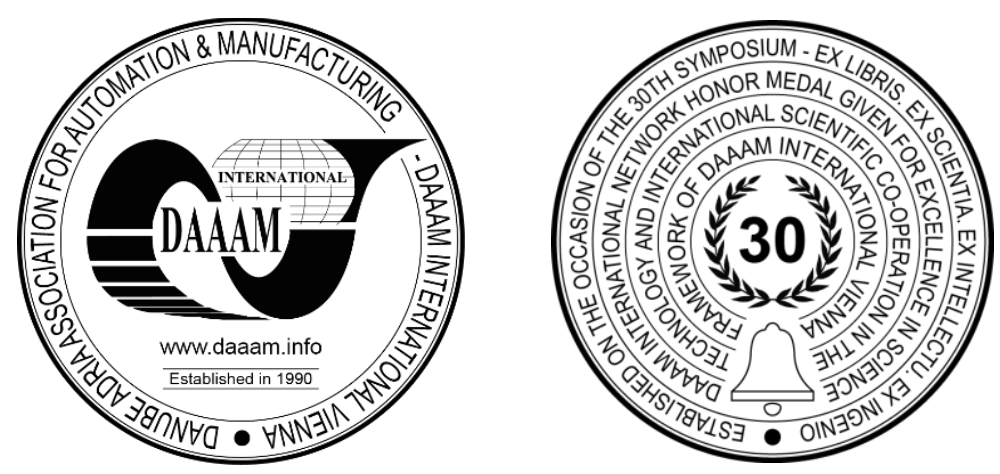

This Publication has to be referred as: Khelemendik, R[oman] \& Pryanichnikov, V[alentin] (2020). Contradictory Reasoning Connecting with the Problems of Intelligent Robotronics, Proceedings of the 31st DAAAM International Symposium, pp.0276-0281, B. Katalinic (Ed.), Published by DAAAM International, ISBN 978-3-902734-29-7, ISSN 1726-9679, Vienna, Austria

DOI: $10.2507 / 31$ st.daaam.proceedings.038

\begin{abstract}
The paper describes the mechanisms and provides examples of arguments, that are considered contradictory from the point of view of classical logics. Models of such reasoning, related problems of intelligent robotronics are shown, and the ways to solve them using the IGEC-methodology are proposed. For contradictory reasoning, constructive fragments are highlighted and the possibilities of their applications in describing and solving problems arising in control systems for mobile service robots and in industrial applications are shown.
\end{abstract}

Keywords: Intelligent robotronics and mobile service robots; IGEC- methodology; B-logic; contradictory reasoning; logical analysis.

\section{Introduction}

The Keldysh Institute of applied mathematics of the Russian Academy of Sciences and the International Institute of new educational technologies (MINOT RSUH) have been conducting joint research in the field of so-called "Intelligent robotronics" for a number of years in order to create methods of heuristic deduction, new educational technologies, and the implementation of software and hardware robotic systems. DAAAM International Vienna and universities such as MSTU "Stankin" participate in this work. As part of this project, a technology for implementing robotariums and production management complexes was created with a logical analysis of the feasibility of recipes and the consistency of actions of operators and technologists. The system of rapid prototyping of the Amur-307 service mobile robot for telemedicine, transport and security applications has been developed. All these works are based on the IGEC methodology ([1], [2], [3], [4], [22]) which combines four logical paradigms, that are conventionally related to the ancient Indian, ancient Greek, Egyptian, and Chinese reasoning traditions. The article discusses the extension of IGEC for working with contradictory reasoning, shows the ways of its application in the problems of intelligent robotronics.

\section{Actual problems in the field of intellectualization of robotic systems}

The development of intelligent robotronics, which is a young scientific and applied discipline, is naturally associated with a variety of problems. At the same time, as practice shows, the successful solution of only technical problems does 
not always lead to an increase in the intelligence of robotic systems. For example, increased performance and the ability to parallelize calculations can lead to new types of errors, synchronization problems, and even slow down calculations.

The field of actual problems of intelligent robotronics (IR) is so wide and diverse that it makes sense to look at the nature and causes of such problems. Thus, the work [23] investigated the logical side of these problems, questions of evidence in reasoning. The works [16], [17], [18] suggested ways, methods and tools for solving these problems. However, the development of IR is currently largely associated with increasing involvement in communication with humans, intelligent robotic systems acquire so-called "human features", which creates a number of new challenges and problems. Among other key problems, we will highlight the construction of new heuristic deduction mechanisms, that minimize iterative procedures, increase the flexibility of interfaces between operators and robots, and effectively analyze conflicting data from various sources.

From the examples discussed in [22] et al., it becomes clear that in many problems it is necessary to construct a system of production rules for eliminating contradictions, and the apparatus of traditional logic is insufficient - the interpretation of data and the goals of reasoning change. In this regard, we developed a new IGEC approach. IGEC methodology (see [1], [2], [3], [4], [6]) is a combination of the four main areas of mathematical approaches, conventionally called ancient Indian, ancient Greek, ancient Egyptian, and ancient Chinese. Since each of these approaches (methods) can be applied independently in General, a holistic, generally four-dimensional representation of expert knowledge of research problems and methods is possible in the IGEC. This representation significantly increases the reliability of solving problems in intelligent robotronics (see [7], [8], [9], [10], [11], [12], [13], [14]), the level of detail and accuracy of models, and also provides tools for formalizing methodological ("intertraditional") contradictions and ways to eliminate them.

At the same time the improvement and application of the IGEC faces a number of challenges and problems. Thus, the growth of types of mechatronic devices, integration software, and applications of intelligent robots creates problems of analysis and design of information-measuring and control systems, training of specialists, and adaptation of operators and users to manage complex systems. In many areas of knowledge, it is necessary to solve very quickly sometimes unexpected, responsible, poorly formalized problems, for example, to understand inconsistent, chaotic instructions; to restore the omission of premises, statements and conclusions; to deal with a change in the subject of discussion, to answer the questions "who is acting - a robot or a person?", how the student or knowledge engineer will act with the robot, etc. To work with these and other problems, this article offers a seemingly paradoxical approach, that uses the ideas of the so-called B-logic, focused on working with contradictory reasoning.

\section{Description of contradictory reasoning using B-logic}

According to classical (Aristotelian) logic, every statement that allows a true/false evaluation cannot be true and false at the same time. From the axioms of propositional logic, predicate logic, linear time logic, etc. one can deduce the theorem that anything follows from a contradiction. Thus, the presence of a contradiction in the reasoning of a mathematical conclusion usually indicates a previously made error, which leads to the termination of this conclusion. Nevertheless, humanity in literature, mythology, sociology, psychology and other fields has accumulated a wealth of experience and examples of so-called contradictory reasoning and decision-making methods in the presence of contradictions. As an independent discipline, contradictory reasoning is studied in the work of MIPT Professor D. V. Beklemishev (see [15]). In this article, the author defines special rules in a light style full of vivid examples, calling them the laws of the so-called "female logic" and conducts some classification of them, focusing on the manifestation and application of this logic during disputes. Note that the term "female logic" it is not defined and in some circles may be interpreted too narrowly, may be perceived as discrimination, so we will call the logic described by Beklemishev $B$ logic.

Noting the importance of the classification carried out in this direction, we believe that at present the areas of manifestation and application of B-logic can be significantly expanded. Since a dispute can be considered as a special case of interaction (game, confrontation) between two or more parties, which for some types of problems can be formalized (for example, in special logical languages - see [16], [17], [18]), we find it interesting to expand the constructive application of B-logic. Following the work of [22], we will consider the main concepts and statements of this article in more detail, and then highlight their areas of application in order to expand the IGEC methodology.

The rules of the dispute on the basis of B-logic. When describing a Dispute based on B-logic, according to [15], three rules are distinguished. Rule 1: a statement that remains unanswered is proven; the speed, weight, and personal direction of the judgments are also taken into account. Rule 2: the party with the last word wins the entire argument; in the dispute cannot go back to what was said earlier. Rule 3: in B-logic, each statement can be either refuted or rejected; in the latter case, it is recognized as meaningless and simply ignored.

Proofs of General propositions and their refutations by examples. On this issue in [15], the following regularities are identified, expressed in a simplified form: 1) if one example does not always prove a General statement, then two examples prove it (in any case); 2) a contradicting example does not refute anything (since it is only one, and one example does not say anything).

The law of repetition of the argument in the B-logic. According to [15], in B-logic, the evidential power of an argument when it repeated changes according to a rather complex law. Most often it grows, but sometimes it falls catastrophically. When repeating an argument, you should give it a new verbal expression each time. 
It looks simular to the biological mechanizm ADA - Akseptor of Dominating Action, while any cell is blocking all stimuls lower, then threshhold, but is activating due the only one stimul, as it reach threshhold (also effect of repeating knocks).

Interpretation of statements in B-Logic. In the simplest case, from the point of view of propositional logic, we are talking about the meaning of elementary statements - propositional (Boolean) variables. According to [15], the question of recognizing a particular statement as true is entirely determined by the goal set. So, in the example of recognizing the color of the collar as black, the wife in a dialogue with her husband recognizes this statement as true (so that he takes and gives the shirt to wash), while in a subsequent dialogue with the housekeeper, she recognizes this statement as false (calling the collar white - so that the housekeeper does not find the shirt too dirty and agrees to wash it).

Moving to another plane. According to [15], the essence of moving to another plane is to change the subject of reasoning as little explicit as possible. Using examples, the author illustrates the technique of this technique in B-logic, especially highlighting the dispute, the purpose of which is "to find out who is right and who is wrong in General, and not on any particular issue".

Syllogisms. According to [15], syllogisms in B-logic are auxiliary in nature and the party applying B-logic should agree with the premises (and conclusions) not unconditionally, but conditionally - depending on what the conclusion is supposed to be and whether it will suit this party. This conditional agreement with the premises allows in B-logic to make a return of these premises and syllogisms back (reject, refute), if the final conclusion is not favorable, i.e. act by analogy with the above rules of dispute and interpretation of statements. That is to see only what I want to see.

Absolute in B-logic. Consideration of the previous concepts, rules, and laws of B-logic leads to the formulation of questions: which of several possible conclusions should be drawn? What are the selection criteria? Thus, according to B-logic distinguishes between true, false and uninteresting (not worthy for attention) judgments. How do statements in B-logic easily and confidently relate to one of these three classes? To answer these and other questions, [15] introduces the so-called absolute, which is "a set of statements used to verify the truth of other statements in the following way: a statement is true if it agrees with the absolute, false if it contradicts it, and does not deserve attention if it has nothing to do with the absolute". At the same time, the author notes, that the absolute is not constant, can change arbitrary and abruptly, and, as a rule, is contradictory from the point of view of classical logic, although in B-logic all statements are "by definition" true (since they are included in the absolute). Using the concept of the absolute, following D.V. Beklemishev, we can assume that a person absorbed in B-logic can easily be convinced of a statement that does not deserve attention, but "it is absolutely impossible to convince of a statement that contradicts the absolute".

\section{B-logic and intelligent robotronics}

In the previous section, we noted some paradoxical examples and strategies for solving problems in B-Logic, now show the possibilities of their (schematic) description in terms of the IGEC methodology. Then for the resulting extension of the methodology IGEC we will consider the issues of correctness and application of methods in the problems of intelligent robotronics.

The rules of the dispute on the basis of B-logic have a fairly broad interpretation and scope of application in intelligent robotronics. Thus, the third rule has an analog both in mathematical logic and discrete mathematics - the allocation of fictitious variables (see [19]), and in IGEC technology (see [3], [17]) - when a statement is recognized as not essential within one of the dimensions. The second rule applies to the study of the functioning of sensory and control systems with a short set of stored data, artificial intelligence systems, that have the property of non-deterministic forgetting and respond only to the last stimulus. In variations on the theme of the first rule, we get that if the opponent is reliable enough (for example, a robot equipped with a program for checking numerical calculations, logical inference), then the absence of objections can signal that it is out of the working state, losing communication, moving to another plane (see below), going beyond the subject area, the response time range; we also note the importance of this rule in the study and modeling of modern TV talk shows, activity and disputes in social networks, to which artificial intelligence is voluntarily or unwittingly attracted.

Proofs of General propositions and their refutations by examples. These considerations are certainly worthy of attention and study in the field of their applicability. So, one of the reasons for proving by a pair of examples is to coordinate these examples with the specific course of current reasoning and aspirations in B-logic. Further, the B-logic can be considered as multidimensional and unfolding over time; therefore, generally speaking, when refuting, at least examples are needed that relate to each of the four dimensions, if the IGEC methodology is followed. We suggest that the laws of classical logic are valid in the ancient Greek dimension; the areas of validity of the laws of B-logic require special consideration.

The law of repetition of the argument in the B-logic. It is easy to see that this law is fair in terms of training, education, processing and securing the necessary amount of information. At the same time, the short-term and fragmentary nature of attention in the perception of information is constantly increasing, so the same thing must be repeated regularly, presenting it in a suitable form for a particular situation. IGEC tools help to solve this urgent problem. For example, for a new argument expression, it is interesting to pass through the IGEC measurement vectors in a cycle or spiral. 
Interpretation of statements in B-Logic. In our opinion, the meaning of Boolean variables in Logic is not always determined by the goal: for example, it can be determined by the current moment of time selected by the ray (plane) of the IGEC measurement. Thus, the Computation Tree Logic (CTL) and IGEC allows us to formalize such changes in the interpretation of the truth of statements, while at the same time finding out their consistency with the goal (also written in logical language).

Moving to another plane. Note that six two-dimensional planes of the IGEC space were introduced in [3] in order to coordinate the work of each pair of the four approaches in the IGEC methodology, in particular, to eliminate the socalled methodological contradictions within the same task (subject of reasoning). So the transition to another plane generally does not mean a change in the subject of reasoning; we consider such a transition as a change in language and combinations of approaches to the study of this subject (including without any connection with the dispute). In addition, in the detail-oriented IGEC methodology, one of the parties can win, for example, in the ancient Egyptian dimension (current recognition by authorities, the fact of writing on "papyrus"), but be defeated in ancient Greek (incorrect logical reasoning and mathematical statements); and Vice versa. Thus, the purpose and implementation of the transition to another plane for specific situations require clarification. As an example of ambiguity in the interpretation of the transition to another plane, we give in B-logic the following well-known dialogue, the essence of which will be explained later. D1. Mary: "I have three sons, the product of their whole ages is 36, and the sum is the number of windows on that house over there". Jane (after looking closely at this house): "So what?" Mary: "And the older one is red". And then Jane named the age of each son.

Syllogisms. According to [20] (p. 171) "... as a rule, logic in live speech is densely shrouded in emotions", which gives a rich ground for defaults, omission of premises, and ultimately provides the opportunity to choose exactly those syllogisms, that lead to a favorable result for the party applying B-logic. However, the question of the fairness, objectivity, and truth of such a result usually requires additional specific study. However, we note that there are also fundamental mathematical results that depend on the premises - the continuum hypothesis, Euclid's/Lobachevsky/Riemann geometries, in which, however, the premises are made into axioms, and in the future the use of syllogisms is regulated by the rules of Aristotelian logic.

Absolute in B-logic. We consider that the absolute in B-logic cannot be characterised by a set of axioms as it is done in classical logic - the presence of contradictions with fixed rules of inference will lead to all possible conclusions, whereas in B-logic, not everything follows from the absolute. However, in some cases, the description and modeling of the absolute one can approximate - in such cases, we will talk about the image of the absolute. Thus, in the IGEC space, a successful formalization of the constant part of the absolute is possible (see examples of resolving contradictions in the ancient Greek-Egyptian and ancient Chinese-Indian planes in [3], [4], [11]) - obtaining the image of the absolute. And the use of time logics (LTL, CTL) allows you to model the change of the absolute in time. An example of the image of the absolute in robotics is the prohibition of robot damage to humans.

\section{Extending the IGEC methodology}

Let's briefly list the ways to extend the IGEC methodology, which were considered during the formalization of reasoning in the previous section. First, it is the formalization and constructive application of the rules of B-logic of behavior in conflict situations (disputes). Second, understanding the features of proof in B-Logic of General statements and their refutation by examples, as well as the law of argument repetition. Third, dynamic and multidimensional interpretation of statements together with the rules of transition to another plane and methods of working with syllogisms in B-logic. Fourth, it is the selection of the absolute in B-logic and obtaining its formalized approximation the image of absolute.

Note that the extensions of the IGEC methodology we have indicated are not complete in terms of formalization and constructive application of B-logic. So, continuing to study the example of dialogue (D1) in B-logic from the subsection "transition to another plane", we notice, that all the mechanisms of formalization of B-logic discussed above do not help in reasonings and drawing conclusions in this case. Indeed, a cursory examination gives the impression that this dialogue lacks syllogisms and only obscure transitions to different planes occur. However, upon careful analysis, we note that among all the triples of natural numbers that give in the product 36 , there are exactly two combinations with the same sum: $\langle 1,6,6\rangle$ and $\langle 2,2,9\rangle$. This explains Jane's question, Mary's subsequent remark, and Jane's final correct answer $-\langle 2,2,9\rangle$. To transfer the skills of conducting such reasoning and problem solving in intelligent robotronics you need both the ability to "cut off information noise" in B-logic, and, using reflection, go to a higher level - the metalevel. Such a resource can be ideas and methods of supercompilation (see [21]) in the sense of "supervised computing", transferred to the formalization of reasoning in B-logic.

\section{Application of the IGEC methodology in project "Intelligent robotronics"}

The extended IGEC methodology and the considered approaches were applied in creating effective technologies for the intellectualization of sensor and control systems. In particular, the four-dimensional IGEC space, together with methods for identif ying and working with contradictions, was actively used in the development and implementation of robotariums ([2], [7], [8], [9], [13]), in complex hardware and software systems ([5], [10], [11], [12], [13], [14], [18], [22], [24], [25]), in new educational technologies ([1], [2], [9]). 
It should be noted that the developed software and hardware systems, design methods and research of actual problems of robotics intellectualization have been tested and realized in the implementation of actual projects (see [1], [2], [4], [5], [7], [8], [9], [10], [11], [12], [13], [14], [17], [18], [22], [24], [25], fig. 1).

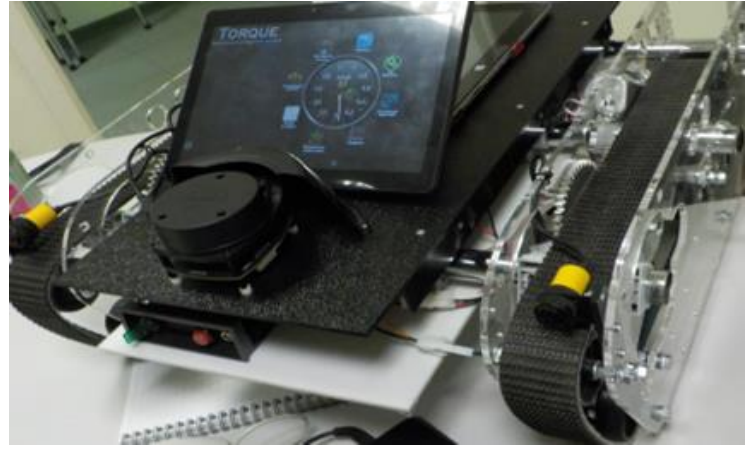

a)

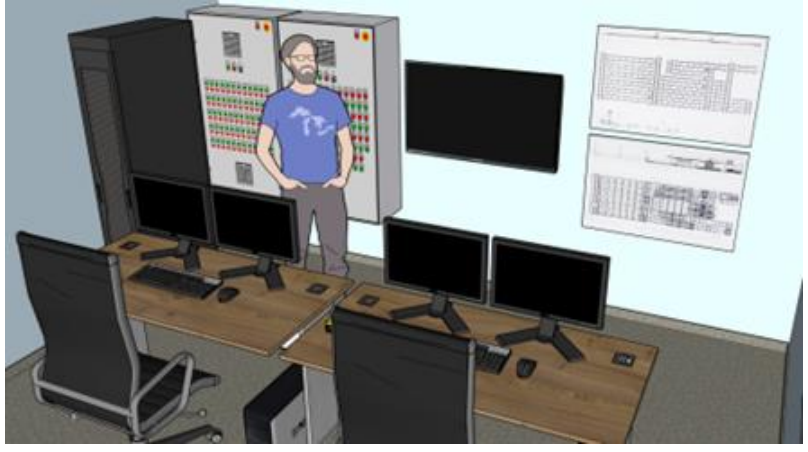

b)

Fig. 1. a) Mobile Service robot Amur-307, realized for telemedical applications; b) Implementation of the Industry-4.0 management system with logical support for protection against incorrect decisions.

\section{Conclusion}

The paper considers the mechanisms of contradictory reasoning and presents an extension of the IGEC methodology based on the ideas of formalization and constructive application of a fairly wide class of natural reasoning. For the 7 types of contradictory reasoning described, the positive and negative aspects of these arguments are considered. For negative fragments, the ways of their identification, formalization and elimination of contradictions are shown. In addition, some original (positive) fragments of contradictory reasoning from the point of view of intelligent robotronics are noted and the possibilities of their further constructive application within the framework of the IGEC methodology are suggested. For the proposed extension of the IGEC methodology, its applications in the problems of intelligent robotronics are shown.

\section{References}

[1] Pryanichnikov V.E., Katalinic B., Kirilchenko A.A., Khelemendik R.V., Kuvshinov S.V., Vician D., Uglesic A. (2015). New Creative Educational Technologies for Inter-university Network // 25th DAAAM International Symposium on Intelligent Manufacturing and Automation. 2014. — Procedia Engineering. 2015. — Vol. 100, — P.259-268. — URL: http://www.sciencedirect.com/science/article/pii/S1877705815003938

[2] Pryanichnikov V. E., Bielic T., Vican D., Katalinich B., Kirsanov K. B., Kuvshinov S.V., Marzanov Yu., Poduraev J. V., Khelemendik R. V., Prysev E. A., Uglesic A., Kharin K.V. (2015). Development of educational technology and the network of associated laboratories of robotarium // Information-measuring and control system. - 2015. - Vol. 13, No. 7. - Pp. 7-25. ISSN 2070-0814.

[3] Pryanichnikov V. E., Khelemendik R. V. (2016). IGEC Information technology and pentalogics // Computer science and information technology: Proceedings of the international conference. science. Conf. - Saratov: Publishing center "Science", 2016. Pp. 331-333.

[4] Khelemendik R.V., Pryanichnikov V.E. (2017). On the IGEC-technology and its application in the study of chess endings // Nauchnyi servis v seti Internet: trudy XIX Vserossiiskoi nauchnoi konferentsii (19-24 sentiabria 2017 g., g. Novorossiisk). - M.: IPM im. M.V. Keldysha, 2017. - S. 446-455. (Scientific service on the Internet: Proceedings of the XIX all-Russian scientific conference (September 19-24, 2017, Novorossiysk). - Moscow: KIAM Keldysh Inst., 2017.) — URL: https://keldysh.ru/abrau/2017/proc.pdf.

[5] Shipovalov E. A., Pryanichnikov V. E. (2017). Auto-planning of missions of mobile robots by onboard computer complexes with hybrid architecture // Extreme robotics. / Collection of abstracts of the International scientific and technical conference. - St. Petersburg: Publishing and printing complex "Gangut", 2017. - Pp. 119-120.

[6] Kirillchenko A.A., Pryanichnikov V.E., Rogozin K.V. (2013). Limits of validity and reliability of proofs. Scepticism in mathematics, functions, and traditions // Intelligent Information-Measuring and Control Systems. 2013. V. 11. № 4. P. 57-65.

[7] Pryanichnikov V. E. (2018). Artificial intelligence and software and hardware robotic systems. Informationmeasuring and control systems. - 2018. - Vol. 16, No. 12. - Pp. 3-11. ISSN 2070-0814.

[8] Kuvshinov S. V., Pryanichnikov V. E., Khelemendik R. V., Kharin K. V., Eprikov S. R. (2018). Robotariums: scientific and technological base of "Intelligent robotronics" // Information-measuring and control systems. - 2018. - Vol. 16, No. 12. Pp. 12-23. ISSN 2070-0814.

[9] Katalinich B., Ksenzenko A.Ya., Kuvshinov S.V., Marzanov Yu.S., Prysev E.A., Pryanichnikov V.E., Khelemendik R.V., Epricov S.R. (2016). // Development of distributed software-hardware robotarium. Extreme 
robotics. // Proceedings of the International scientific and technical conference. (November 24-25, 2016, StPetersburg) - Saint Petersburg: OOO"AP4Print", 2016. - 480 p., P.459-465. ISBN 978-5-9909163-3-3.

[10] Pryanichnikov V.E., Chernyshev V.V., Arykantsev V.V., Aryskin A.A., Eprikov S.R., Ksenzenko A.Ya., Petrakov M.S. (2018). Enhancing the Functionality of the Groups of Autonomous Underwater Robots // Proceedings of the 29th DAAAM International Symposium, 2018. — DAAAM International, Vienna, Austria, 2018. — P.1319-1325. DOI:10.2507/29th.daaam.proceedings.190.

[11] Pryanichnikov V.E., Aryskin A.A., Eprikov S.R., Kirsanov K.B., Khelemendik R.V., Ksenzenko A.Ya., Prysev E.A., Travushkin A. S. (2017). Technology of Multi-Agent Control for Industrial Automation with Logical Processing of Contradictions // Proceedings of the 28th DAAAM International Symposium, 2017. — DAAAM International, Vienna, Austria, 2017. — P.1202-1207. DOI:10.2507/28th.daaam.proceedings.167 .

[12] Ksenzenko A.Ya., Pryanichnikov V.E., Prysev E.A., Chernyshev, V.V. (2017). Design the Contactless Charger and Contactless Data Transfer between Underwater Robot-Satellits and Underwater 6-Legged Vehicle, Proceedings of the 28th DAAAM International Symposium, pp.1197-1201, B. Katalinic (Ed.), Published by DAAAM International, ISBN 978-3-902734-11-2, ISSN 1726-9679, Vienna, Austria. DOI: 10.2507/28th.daaam.proceedings.166.

[13] Pryanichnikov V.E., Ksenzenko A.Ya., Kuvshinov S. V., Poduraev Yu. V., Prysev E.A., Khelemendik R.V., Eprikov S.R. (2018). Intelligent robotronics: hardware-software complexes of robotariums // Proceedings of the 27th DAAAM International Symposium, 2016. — DAAAM International, Vienna, Austria, 2018. — P.0225-0229. DOI:10.2507/27th.daaam.proceedings.033.

[14] Bogdanovich A.V., Kirsanov K.B., Pryanichnikov V.E., Khelemendik R.V. (2018). Hardware-Software components of intelligent service mobile robots / Information-measuring and control systems (Intelligent and adaptive robots, vol. 14, № 1-2, 2019), M.: Radiotechnika, 2018, vol. 16, № 12, p. 33-39. ISSN 2070-0814.

[15] Beklemishev D.V. (1992). Zametki po zhenskoi logike // Fiziki vse eshche shutiat. Sbornik. / Pod red. V.F.Turchina. - M.: Maket, 1992. -S. 142-151 [In Russian].

[16] Khelemendik R.V. (2006). An algorithm for determining satisfiability formulae of computation tree logic and an effective algorithm for constructing derivations of valid formulas from axioms. Mathematical Issues of Cybernetics, no. 15, A collection of papers, ed. by O.B.Lupanov. Moscow: Fizmatlit, 2006, pp. 217-266.

[17] Khelemendik R.V., Pryanichnikov V.E. (2018). O postroenii spetsialnogo logicheskogo iazyka dlia zadach intellektualnoi robotroniki i issledovaniia bolshikh formul // Kompiuternye nauki i informatsionnye tekhnologii: Materialy mezhdunar. nauch. konf. — Saratov: Izdat. tsentr «Nauka», 2018. — S. 425-428.

[18] Pryanichnikov V.E., Aryskin A.A., Ksenzenko A.Ya., Petrakov M.S., Ignatiev V.A., Khelemendik R.V. (2018). Design of a service autonomous mobile robot, based on the control with logical analysis of operations feasibility // Nauchnyi servis v seti Internet: trudy XX Vserossiiskoi nauchnoi konferentsii (17-22 sentiabria 2018 g., g. Novorossiisk). - $\quad$ M.: IPM im. M.V. Keldysha, 2018. - - S. 428-437. - URL: https://keldysh.ru/abrau/2018/proc.pdf.

[19] Yablonskii S.V. (1986). Vvedenie v diskretnuiu matematiku / M.: Nauka, 1986. — 384s.

[20] Pukhnachev Iu.V., Popov Iu.P. (2007). Matematika bez formul: Kniga vtoraia / M.: KomKniga, 2007. — 240s.

[21] Klimov A.V., Romanenko S.A. (2018). Superkompiliatsiia: osnovnye printsipy i bazovye poniatiia (Supercompilation: main principles and basic concepts) // Preprinty IPM im. M.V. Keldysha. 2018. № 111. 36 s. URL: https://library.keldysh.ru/preprint.asp?id=2018-111.

[22] Khelemendik R.V., Pryanichnikov V.E., Sivakova T.V. (2019). On the extension of the methodology IGEC and its applications in the problems of intelligent robotronics // Nauchnyi servis v seti Internet: trudy XX Vserossiiskoi nauchnoi konferentsii (23-28 sentiabria 2019 g., g. Novorossiisk). - M.: IPM im. M.V. Keldysha, 2019. — S. 639-652. — URL: https://keldysh.ru/abrau/2019/proc.pdf.

[23] Kirillchenko A.A., Rogozin K.V. (2013). Limits of validity and reliability of proofs. Dilemmas, errors, computer // Intelligent Information-Measuring and Control Systems. 2013. V. 11. № 4. P. 66-73.

[24] Pryanichnikov V.E. Chernyshev V., Davydov O.I., Katalinic B., Khelemendik R.V., Kharin K.V., Kuvshinov S.,V., Roganov A., Travushkin A. (2019). Intelligent Robotronics - Methodology for Solving Logical Problems of Service Robots // Proceedings of the 30th DAAAM International Symposium, pp.1131-1135, B. Katalinic (Ed.), Published by DAAAM International, ISBN 978-3-902734-22-8, ISSN 1726-9679, Vienna, Austria DOI: 10.2507/30th.daaam.proceedings.158.

[25] Aryskin A.A, Bogdanovich A.V., Davydov O.I. Khelemendik R.V. (4), Petrakov M.S., Pryanichnikov V.E. (5), Tarasov R. (2019). Control and interaction algorithms for industrial and service robots // Chapter 33 in DAAAM International Scientific Book 2019, pp.377-384, B. Katalinic (Ed.), Published by DAAAM International, ISBN 978-3-902734-24-2, ISSN 1726-9687, Vienna, Austria DOI: 10.2507/daaam.scibook.2019.33. 